\title{
CARACTERIZAÇÃO MINERALÓGICA EM MINÉRIO DE TÂNTALO E NIÓBIO DE PORTO GRANDE - AP
}

\author{
J. P. P. SILVA, R. P. SILVA e L. D. A. S. MEIRA \\ Instituto Federal de Educação, Ciência e Tecnologia do Amapá. \\ joao.silva@ifap.edu.br - robertop.silva@hotmail.com - lidia.meira@ifap.edu.br
}

Artigo submetido em novembro/2013 e aceito em junho/2014

DOI: http://dx.doi.org/10.15628/holos.2014.1835

\section{RESUMO}

O Este trabalho apresenta resultados do estudo de caracterização mineralógica em duas amostras de minério Tantalita-Columbita. A metodologia utilizada para a realização deste estudo envolveu a execução de análise granulométrica do material "in natura" na série Tyler de 100\#; 150\#; 200\# e 325\# mesh, separação mineral em líquido denso, seguido do estudo químicomineralógico por meio de fluorescência e difração de raios $\mathrm{X}$, visando identificar as fases minerais presentes. A coleta das amostras foi pontual, realizada na cabeceira da margem de uma drenagem e numa profundidade de 70 $\mathrm{cm}$, onde constituiu a primeira amostra. Já a segunda amostra foi composta após três sequencias de bateia, constituindo um concentrado de bateia. As amostras estudadas apresentam diferentes teores de Ta; $\mathrm{Ti} ; \mathrm{Fe} ; \mathrm{Zr}$ e $\mathrm{Nb}$, a maior diferença observada refere-se ao aumento do teor de tântalo e titânio e diminuição do conteúdo de silício. Trabalhos empíricos e de forma rudimentar realizados nesta região indicaram teor de tântalo, após bateiamento, entre 50 a $55 \%$.

PALAVRAS-CHAVE: Caracterização de minério; tântalo; nióbio; meio denso.

\section{MINERALOGICAL CHARACTERIZATION IN ORE TANTALUS AND NIOBIUM OF PORTO GRANDE - AP}

\begin{abstract}
This work presents the results of mineralogical characterization studies on two ore samples TantaliteColumbite. The methodology used for the studies involved the execution of analysis characterization in size distribution in Tyler series of 100\#; 150\#; 200\# and 325\# mesh, mineral separations by liquid heavy, followed by chemical-mineralogical studies using fluorescence and $\mathrm{X}$ ray diffraction, aiming identify the minerals phases present. The sample collection was punctual, realized at the head margin of the drainage and a depth of $70 \mathrm{~cm}$,
\end{abstract}

where was constituted the first sample. Already the second sample was composed after three bateia sequences. The studied samples present different content different concentrations of $\mathrm{Ta} ; \mathrm{Ti} ; \mathrm{Fe} ; \mathrm{Zr}$ and $\mathrm{Nb}$, the largest difference observed refers to the increase in the content of tantalum and titanium and decrease of the content of silício. Empiric work and primitive form realized this region indicate, after bateiamento, content of tantalum between 50 to $55 \%$.

KEYWORDS: characterization of ore; tantalum; niobium; dense medium. 


\section{INTRODUÇÃO}

O Brasil é o maior produtor mundial de nióbio, seguido pelo Canadá e Austrália, e responde por $98 \%$ da demanda mundial. O nióbio possui afinidade geoquímica com o tântalo, o que permite que sejam encontrados juntos na maioria deste minério. O principal mineral destes elementos é denominado de tantalita quando apresenta teor mais elevado de tântalo ou columbita quando o teor de nióbio prevalece (Rodrigues, 2009).

O tântalo é um elemento metálico com características como extraordinária resistência ao calor, alta capacitância elétrica, altíssima resistência à corrosão e à intrusão química. Seu principal uso, sob a forma de pó, é na manufatura de capacitores empregados em telefones celulares, computadores, pagers, telas de TV, câmeras digitais, entre outros. Por outro lado, sob a forma de metal, é empregado na manufatura de lâminas de turbinas a jato, peças de mísseis e reatores nucleares, entre outros (Lima, 2009).

Segundo Oliveira (2010), no estado do Amapá a extração da tantalita vem sendo desenvolvida e ocupa a segunda posição entre os minerais mais explorados por atividade garimpeira. Os municípios que apresentam ocorrência deste mineral são: Calçoene, Pedra Branca do Amapari, Tartarugalzinho e Porto Grande.

No município de Porto Grande, registram-se explorações dos minérios de Tântalo e Nióbio de forma empírica, porém indicando percentuais elevados de aproximadamente $50 \%$ destes elementos.

O estudo dos recursos minerais disponíveis e não renováveis é essencial para o seu aproveitamento adequado e, consequentemente, em particular para o município de Porto Grande$A P$, que tem a atividade mineral como uma das principais atividades econômicas.

A caracterização de minérios é uma etapa fundamental para o aproveitamento de recursos minerais de forma otimizada, o que fornece subsídios mineralógicos e texturais necessários para etapas de beneficiamentos. Análises químicas e mineralógicas, bem como separação por liquido denso, são consideradas eficaz na caracterização dos produtos de minérios e de diversas separações (Silva, 2009).

Dessa forma, o trabalho apresenta resultados preliminares de caracterização mineralógica e química em amostras de minério tantalita-columbita do município de Porto Grande - Amapá, visando conhecer sua característica granulométrica, fases constituintes e a distribuição dos elementos ( $\mathrm{Nb}$ e Ta), possibilitando assim conhecer melhor o potencial do minério desta região.

\section{METODOLOGIA}

\subsection{Material}

As amostras foram coletadas na região de Porto Grande-AP na margem da cabeceira de uma drenagem, em uma profundidade de $70 \mathrm{~cm}$. A coleta constituiu-se de forma pontual, obtendose a primeira amostra (01) "in natura". Já a segunda amostra (02) foi obtida após sequencias de bateia, constituindo-se do concentrado de bateia. A figura 1 ilustra o processo de bateiamento realizado com a amostra para obtenção do concentrado de bateia. 


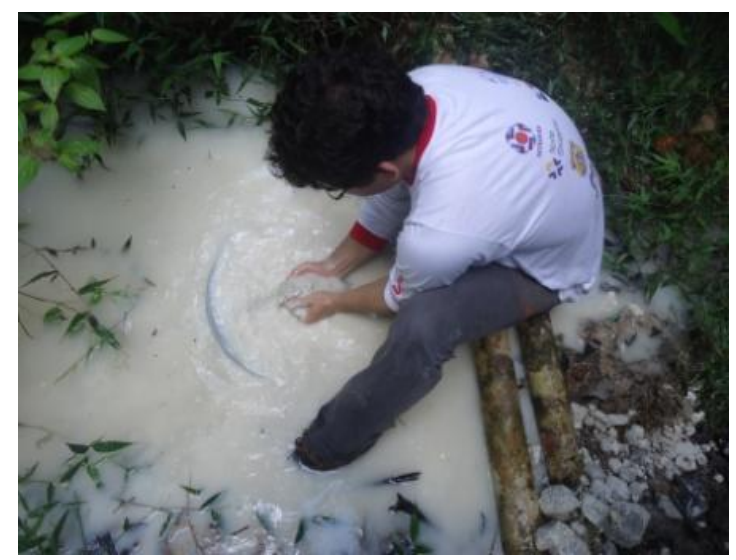

Figura 1. Processo de bateiamento do minério de columbita-tantalita.

O material coletado foi submetido à homogeneização e quarteamento para obter uma distribuição mais uniforme dos constituintes pelo método da pilha cônica, realizado no Laboratório de Tratamento de Minérios e Resíduos do IFRN. Em seguida, foram utilizadas 500g da amostra 01 e $500 \mathrm{~g}$ da amostra 02 como alíquotas representativas. A partir daí, foram realizados os ensaios de caracterização da amostra minério.

A figura 2 mostra o fluxograma de com as etapas realizadas neste trabalho.

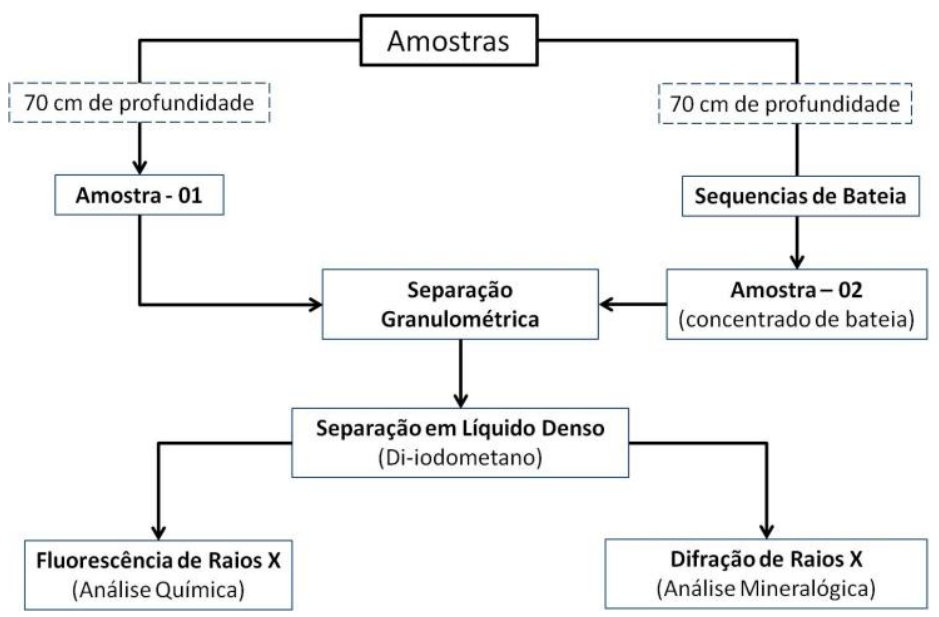

Figura 2. Fluxograma com os passos realizados.

\subsection{Separação granulométrica}

Após de separadas as alíquotas das amostras 01 e 02, foi realizado o peneiramento via úmido. A mostra foi passada em um conjunto de peneiras da série Tyler, com 6 \#; 20 \#; 35 \#; 80 \#; 100 \#; 150 \#; 200 \# e 325 \# mesh. Depois foram removidas todas as frações retidas nas peneiras e, em um recipiente apropriado, secados em estufa na temperatura de $110^{\circ} \mathrm{C}$, por 24 horas. Em seguida foi realizada pesagem de cada fração para o cálculo da distribuição granulométrica. 


\subsection{Separação em líquido denso (Di-iodometano)}

As amostras com granulometria 149, 105 e $74 \mu \mathrm{m}$ foram submetidas a ensaios de separação por meio denso, utilizando-se Di-iodometano: fórmula química: $\left(\mathrm{CH}_{2} \mathrm{I}_{2}\right)$; densidade $\left(3,32 \mathrm{~g} / \mathrm{cm}^{3}\right)$, desdobrando-se cada alíquota em duas frações: flutuados e afundados.

Os ensaios em meio denso foram realizados no laboratório de Análise Química Industrial, Mineral e Ambiental - ANQUIM. A figura 3 ilustra o local onde se realizou a separação em líquido denso.

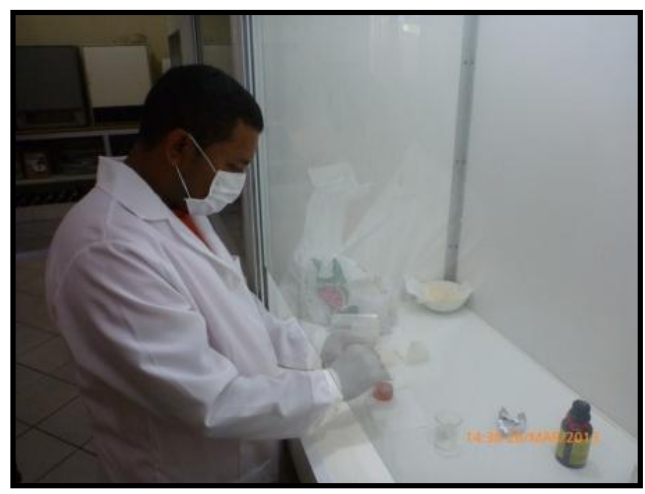

Figura 3. Separação em líquido denso nas amostras 01 e 02 estudadas.

\subsection{Análises química e mineralógica (FRX e DRX)}

Foi usada a técnica de fluorescência de raios-X por energia dispersiva (FRX) para análise química da amostra "in natura" e da amostra concentrado de bateia. As análises foram realizadas no laboratório de processamento mineral de resíduos (LPMR), IFRN, usando o equipamento EDX 720, da marca Shimadzu.

As amostras foram moídas até a granulometria inferior a 200 \# mesh. Os resultados obtidos são apresentados na forma dos óxidos mais estáveis dos elementos químicos presentes.

Para análise mineralógica foi utilizada a técnica difração de raios-X (DRX), com moagem dos materiais abaixo de 200 \# mesh. $O$ ensaio foi realizado no Laboratório de Processamento Mineral e de Resíduos (LPMR) do IFRN, utilizando o equipamento XRD - 7000 da marca SHIMADZU com tubo de $\mathrm{Cu}(\lambda=1,54056 \AA)$, com varredura variando de $2^{\circ}$ a $80^{\circ}$ para $2 \theta$, com velocidade de $2^{\circ} / \mathrm{mim}$.

\section{RESULTADOS E DISCUSSÃO}

\subsection{Distribuição granulométrica}

A distribuição granulométrica por meio da percentagem do passante acumulado em relação à abertura das peneiras utilizadas em micrometros, das amostras 01 (in natura) e 02 (concentrado de bateia), são apresentadas, respectivamente, nas Figuras 4 e 5. 


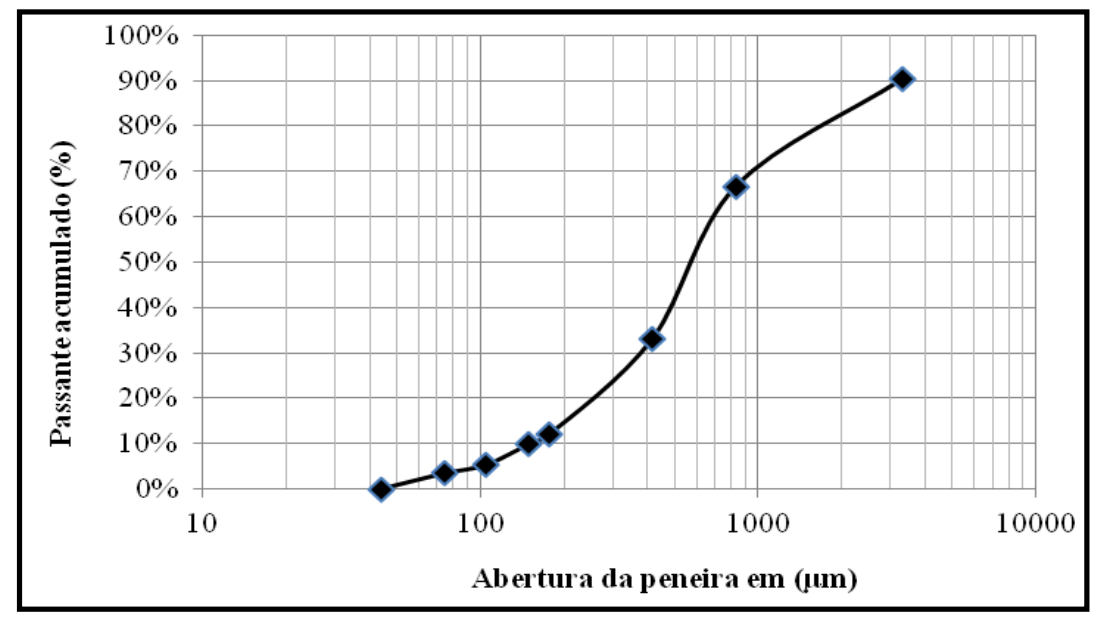

Figura 4. Distribuição granulométrica da amostra "in natura".

A amostra (01) apresentou $10 \%$ de massa retida em 3,32 $\mathrm{mm}$ e $3 \%$ passante em 0,074 $\mathrm{mm}$. Classificando-se, assim, como amostra de granulometria fina. Portanto, não necessitando de etapa de cominuição para obter-se o mineral de interesse com a estimativa de grau de liberação elevado.

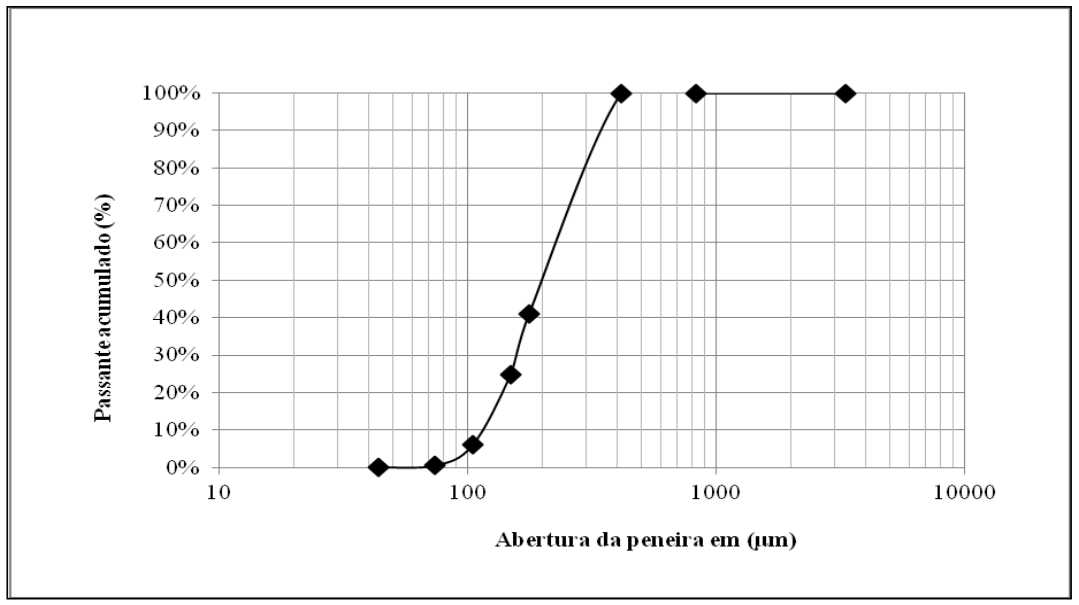

Figura 5. Distribuição granulométrica da amostra concentrado de bateia.

O resultado granulométrico da amostra (02) indicou que $40 \%$ desta tem granulometria menor do que 0,17 mm (80\#). Confirmando-se como amostra de granulometria fina, e dessa forma, com tamanhos interessantes para ser submetida a etapa de concentração mineral.

\subsection{Análise química (FRX)}

A análise química da amostra "in natura" estudada é apresentada na Tabela 1. Já a Tabela 2 mostra a análise da amostra concentrado de bateia.

Tabela 1 - Resultado de análise química (FRX) na amostra "in natura".

\begin{tabular}{c|c|c|c|c|c|c|c|c}
\hline $\mathrm{SiO}_{2}(\%)$ & $\mathrm{Al}_{2} \mathrm{O}_{3}(\%)$ & $\mathrm{K}_{2} \mathrm{O}(\%)$ & $\mathrm{Fe}_{2} \mathrm{O}_{3}(\%)$ & $\mathrm{TiO}_{2}(\%)$ & $\mathrm{SO}_{3}(\%)$ & $\mathrm{ZrO}_{2}(\%)$ & $\mathrm{Ta}_{2} \mathrm{O}_{5}(\%)$ & $\mathrm{NbO}(\%)$ \\
\hline 72,38 & 24,48 & 1,65 & 0,8 & 0,35 & 0,2 & 0,05 & 0,03 & 0,01 \\
\hline
\end{tabular}


Tabela 2 - Resultado de análise química (FRX) na amostra concentrado de bateia.

\begin{tabular}{c|c|c|c|c|c|c|c|c}
\hline $\mathrm{SiO}_{2}(\%)$ & $\mathrm{Al}_{2} \mathrm{O}_{3}(\%)$ & $\mathrm{K}_{2} \mathrm{O}(\%)$ & $\mathrm{Fe}_{2} \mathrm{O}_{3}(\%)$ & $\mathrm{TiO}_{2}(\%)$ & $\mathrm{MnO}(\%)$ & $\mathrm{ZrO}_{2}(\%)$ & $\mathrm{Ta}_{2} \mathrm{O}_{5}(\%)$ & $\mathrm{NbO}(\%)$ \\
\hline 30,43 & 2,10 & 0,10 & 13,67 & 19,28 & 1,22 & 5,54 & 20,78 & 4,07 \\
\hline
\end{tabular}

A amostra do concentrado de bateia apresenta acentuado enriquecimento no teor de tântalo, titânio e ferro, bem como enriquecimento visível no teor de zircônio, nióbio e manganês. Já na amostra "in natura" o teor de silício, alumínio e potássio são os que predominam. De acordo com Pereira et all (2008), que denominaram cristais de columbita-tantalita, em função dos teores destes elementos (nióbio e tântalo), nesse estudo foi observado que o teor do tântalo é mais elevado do que o do nióbio (Tabela 2), considerando-se o mineral em estudo como sendo a tantalita-columbita (Figura 7).

\subsection{Análise mineralógica (DRX)}

Os resultados da difratometria de raios-X realizado nas amostras, "in natura" e concentrado de bateia, são mostrados, respectivamente, nas Figuras 6 e 7.

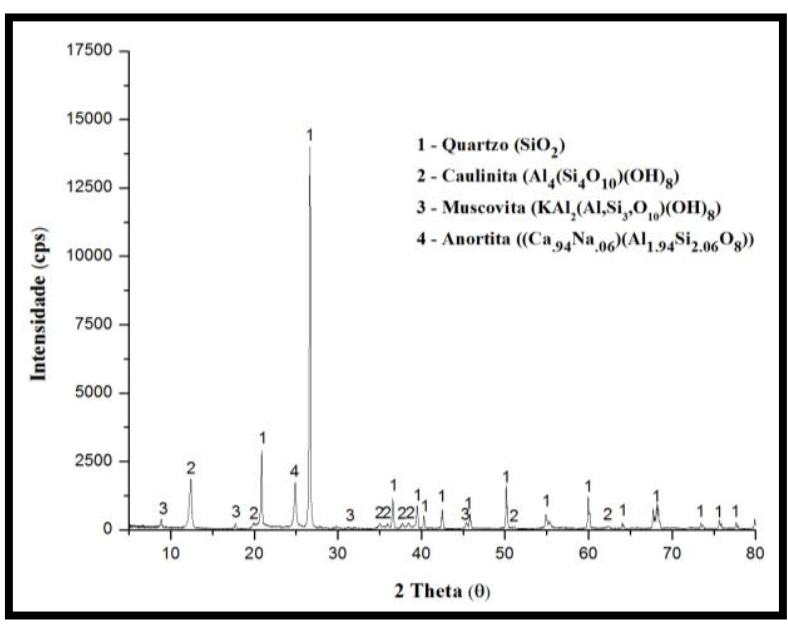

Figura 6. Difratograma de raios- $X$ da amostra "in natura".

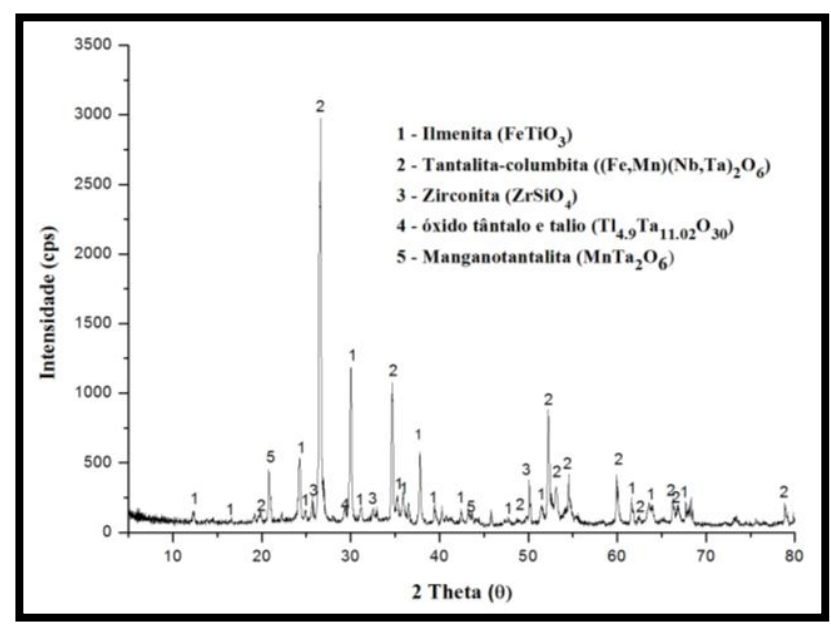

Figura 7. Difratograma de raios-X da amostra concentrado de bateia.

O resultado do (DRX) da amostra "in natura" apresenta minerais como quartzo, caulinita, muscovita e anortita, caracterizando-se como um pegmatito rico em plagioclásios. Já a amostra concentrado de bateia apresenta a partir do (DRX) minerais de metais com ótimas propriedades e grande importância industrial como ilmenita (titânio), tantalita-columbita (tântalo e nióbio), zirconita (zircão), entre outro. No entanto, a fase mineral predominante é a ferro-tantalitacolumbita, tendo em vista que, na análise por FRX o percentual do elemento nióbio é inferior ao dos elementos tântalo e ferro.

\subsection{Separação com líquido denso (Di-iodometano)}

As análises em meio denso realizadas, com a amostra "in natura" e com a amostra concentrado de bateia, nas malhas de 100 \#; 150 \# e 200 \# são mostrados, respectivamente, nas figuras 8 (A) e (B) que indicam o percentual de massa de mineral leve $\left(\mathrm{d}<3,3 \mathrm{~g} / \mathrm{cm}^{3}\right.$ ) e pesado (d $>3,3 \mathrm{~g} / \mathrm{cm}^{3}$ ) em relação à abertura das peneiras. 


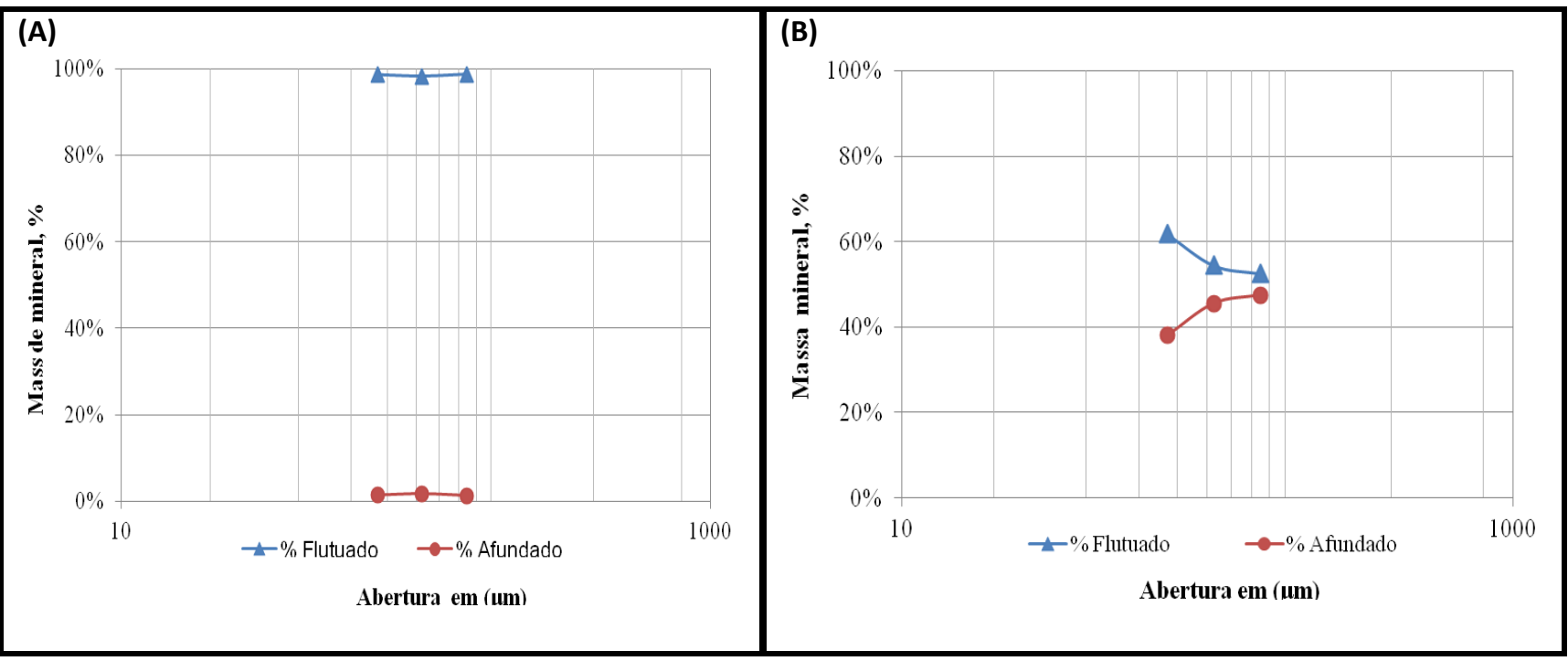

Figura 8. (A) Separação em meio denso da amostra "in natura" e (B) Separação em meio denso do concentrado de bateia.

Os resultados da separação com líquido denso nas malhas de 100 \#; 150 \# e 200 \# mostraram uma diminuição de aproximadamente $50 \%$ de massa dos minerais com densidades menores do que $3,3 \mathrm{~g} / \mathrm{cm}^{3}$. Indicando que os minerais como zircão, ilmenita, tantalita-columbita, entre outros, apresentam-se em maior massa na peneira de 100 \# mesh.

\section{CONCLUSÃO}

A amostra "in natura" do minério de Porto Grande é constituída essencialmente por $\mathrm{SiO}_{2}$ (72\%) com $\mathrm{Al}_{2} \mathrm{O}_{3}$ (24\%) e $\mathrm{K}_{2} \mathrm{O}(1,6 \%)$ subordinados; $\mathrm{Fe}_{2} \mathrm{O}_{3}$ corresponde a 0,8\%; $\mathrm{TiO}_{2}$ e 0,35\%; portanto, representada pelos minerais caulinita, quartzo, muscovita e anortita.

Já a amostra de concentrado de bateia apresenta-se constituída essencialmente por $\mathrm{SiO}_{2}$ (30\%) com $\mathrm{Ta}_{2} \mathrm{O}_{5}$ (20\%); $\mathrm{TiO}_{2}$ (19\%) e $\mathrm{Fe}_{2} \mathrm{O}_{3}$ (13\%) subordinados; $\mathrm{ZrO}_{2}$ corresponde a 5,5\% e $\mathrm{NbO}$ a $4 \%$, deste modo, sendo representada pelos minerais tantalita-columbita, ilmenita, zirconita e outros óxidos de tântalo.

As amostras possuem granulação fina, o que também a torna interessante, pois seu beneficiamento poderá não necessitar de etapas de cominuição, sinalizando para um processo com menores custos. $\mathrm{O}$ teor de elementos como o tântalo, titânio e nióbio são interessantes, pois apenas com o procedimento de concentração por bateia, os seus teores foram elevados. Indicando, assim, para um possível potencial econômico, no município de Porto Grande, precisando ainda ser demonstrado.

\section{REFERÊNCIAS BIBLIOGRÁFICAS}

1. LIMA, J. M. G. Perfil da mineração da tantalita. Desenvolvimento de estudos para a elaboração do plano duodecenal (2010-2030) de geologia, mineração e transformação mineral. MME. Brasília, 2009.

2. OLIVEIRA, M. J. Diagnóstico do setor mineral do estado do Amapá. Instituto de pesquisas científicas e tecnológicas do Estado do Amapá (IEPA). 148p. Macapá, 2010. 
3. PEREIRA, R. M., CASTRO, C., NEUMANN, R. e ÁVILA, C. A. Minerais de metais e elementos raros associados ao granito desemborque, São Paulo. In: Revista brasileira de geociências. Ed: 38; Vol. 4. p591-597. UERJ. Rio de Janeiro, 2008.

4. RODRIGUES, A. F. S. Economia Mineral do Brasil - Brasília-DF: DNPM. 2009.

5. SILVA, J. P. P., PINHEIRO, V. S., ARAÚJO, F. S. D. e LEITE, J. Y. P. Caracterização do rejeito de lavra garimpeira de esmeralda. In: IV Congresso de Pesquisa e Inovação da Rede Norte Nordeste de Educação Tecnológica. Belém - PA. 2009. 